\title{
LITERATURA CLÁSSICA NA ATUALIDADE: PRÁTICAS CURRICULARES INCLUSIVAS NO ENSINO MÉDIO
}

\author{
CURRENTLY CLASSICAL LITERATURE: CURRICULAR INCLUSIVE PRACTICES IN \\ HIGH SCHOOL
}

\author{
LITERATURA CLÁSICA EN LA ACTUALIDAD: PRÁCTICA CURRICULAR INCLUSIVAS \\ EN LA ENSEÑANZA MEDIA
}

Andreia Alexandre Silva Duarte E-mail: profandreiaduarte@gmail.com

\author{
Eliana Marques Zanata \\ E-mail: lizanata@fc.unesp.br \\ UNESP / Campus de Bauru - SP
}

\begin{abstract}
RESUMO
As práticas de ensino que envolvem a literatura clássica na atualidade mostram-se uma proposta desafiadora, uma vez que adolescentes têm diversos atrativos externos, com ênfase nas tecnologias disponíveis e, além disso, professores contam com alunos PAEE (Público-Alvo da Educação Especial) nas salas de aula. O objetivo geral: promover e avaliar as possibilidades de associação da leitura de poema clássico à análise de materiais multimodais, como proposta para a formação do leitor crítico e participativo nas aulas de literatura no Ensino Médio, incluindo os alunos PAEE. Objetivos específicos: apresentar e analisar a proposta de intervenção na área de literatura clássica disponível no Currículo Oficial de Estado de São Paulo; mapear as ações dos alunos que caracterizam seu envolvimento com a atividade proposta; verificar a disponibilidade e ação dos docentes frente à aplicabilidade da atividade proposta. Pesquisa ação-participante de abordagem qualitativa, contou com três docentes de Língua Portuguesa, 42 adolescentes, dos quais quatro caracterizam-se como PAEE. As atividades propostas incluíram: leitura do poema, roda de conversa, musicalização e produção textual espelhada em um poema clássico. Os estudantes com e sem deficiência utilizaram estratégias que contribuíram para a realização das tarefas, demonstrando melhoria na competência leitora. A adoção de práticas de maneira contextualizada motivou os alunos a ler os clássicos com autonomia e protagonismo, impactando a aprendizagem de todos independentemente das especificidades de cada um.
\end{abstract}

PALAVRAS-CHAVE: Literatura. Práticas Curriculares. Multimodalidade.

\begin{abstract}
The teaching practices that involve classical literature today are a challenging proposal, since adolescents have diverse external attractives, with emphasis on the available technologies and, in addition, teachers count on students PAEE (Special Education Target Public) in classrooms. The general objective: to promote and evaluate the possibilities of association of reading classical poem to the analysis of multimodal materials, as a proposal for the formation of critical and participatory reader in literature classes in High School, including PAEE students. Specific objectives: to present and analyze the intervention proposal in the area of classical literature available in the State Official Curriculum of São Paulo; map the actions of the students that characterize their involvement with the proposed activity; to verify the availability and action of teachers in face of the applicability of the proposed activity. Action-participant research with a qualitative approach, had three Portuguese language teachers, 42 adolescents, of whom four are characterized as PAEE. The proposed activities included: reading the poem, conversation wheel, musicalization and textual production mirrored in a classic poem. The students with and without disabilities used strategies that contributed to the accomplishment of the tasks, demonstrating improvement in the reading competence. The adoption of practices in a contextualized way motivated the students to read the classics with autonomy and protagonism, impacting the learning of all regardless of the specificities of each one.
\end{abstract}

KEY-WORDS: Literature. Curricular Practices. Multimodality. 


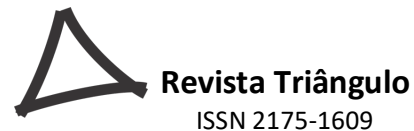

ISSN 2175-1609

Las prácticas de enseñanza que involucran a la literatura clásica en la actualidad se muestran una propuesta desafiante, una vez que los adolescentes tienen diversos atractivos externos, con énfasis en las tecnologías disponibles y, además, profesores cuentan con alumnos PAEE (Público-objetivo de la Educación Especial) en las aulas. El objetivo general: promover y evaluar las posibilidades de asociación de la lectura de poema clásico al análisis de materiales multimodales, como propuesta para la formación del lector crítico y participativo en las clases de literatura en la Enseñanza Media, incluyendo los alumnos PAEE. Objetivos específicos: presentar y analizar la propuesta de intervención en el área de literatura clásica disponible en el Currículo Oficial de Estado de São Paulo; mapear las acciones de los alumnos que caracterizan su implicación con la actividad propuesta; verificar la disponibilidad y acción de los docentes frente a la aplicabilidad de la actividad propuesta. Acción participante en la investigación enfoque cualitativo incluyó tres profesores de portugués, 42 adolescentes, cuatro de los cuales se caracterizan por ser PAEE. Las actividades propuestas incluyeron: lectura del poema, rueda de conversación, musicalización y producción textual reflejada en un poema clásico. Los estudiantes con y sin discapacidad utilizaron estrategias que contribuyeron a la realización de las tareas, demostrando mejoría en la competencia lectora. La adopción de prácticas de manera contextualizada motivó a los alumnos a leer los clásicos con autonomía y protagonismo, impactando el aprendizaje de todos independientemente de las especificidades de cada uno.

PALABRAS CLAVE: Literatura. Práctica Curricular. Multimodalidad.

\section{INTRODUÇÃO}

Trabalhar a literatura clássica na atualidade torna-se uma proposta desafiadora, uma vez que mudanças significativas relacionadas às transformações proporcionadas pelas tecnologias da informação e comunicação (TICs), somada à presença de alunos Público-Alvo da Educação Especial (PAEE) impõem novos desafios à educação escolar, sobretudo ao ensinoaprendizagem de Língua Portuguesa na escola de Ensino Médio.

Os adolescentes têm diversos atrativos advindos de realidades virtuais, visto que uma vasta e complexa circulação de comunicação e informação implica uma variedade de mídias e diferentes modalidades tais como: linguística, visual, gestual e sonora que, por muitas vezes, estão ligadas umas às outras, causando transformações nas formas de funcionamento e configuração dos textos. Assim, mudanças nas maneiras de ler, de produzir e de fazer circular textos trouxeram novos desafios à educação escolar.

O ensino da literatura clássica tem ênfase no Ensino Médio, porém os adolescentes, nessa fase, estão envoltos a diversos atrativos que desviam o propósito de se ler literatura para fruição, tornando-se desmotivados e apenas decorando o que é necessário para ter êxito em provas ou vestibulares. Nesse mesmo contexto, encontra-se o professor que vive o desafio didático de adequar ou ajustar sua prática pedagógica para atender também às necessidades de aprendizagem do aluno PAEE. 


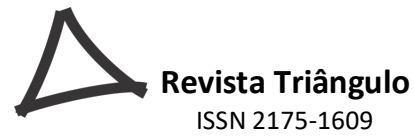

ISSN 2175-1609

Diante dessa realidade, como os educadores podem pensar propostas para enfrentar a desmotivação dos jovens da escola do Ensino Médio em relação à literatura clássica? As práticas educativas são acolhedoras e adequadas para garantir o acesso ao currículo, com qualidade de ensino-aprendizagem para o aluno PAEE?

Nesse contexto, é preciso valorizar práticas pedagógicas que vão ao encontro das expectativas dos adolescentes. Há que se pensar em estratégias pedagógicas que integrem o clássico da literatura, com a significância do aprendizado do conteúdo pelo adolescente e atenda ao PAEE, que está na escola e tem direito a aprender como todos. Desta forma, espera-se alcançar uma prática de ensino que atenda às necessidades de todos os alunos.

Para Glat e Nogueira (2002, p.26), "a inclusão de indivíduos com necessidades educacionais especiais na rede regular de ensino não considera apenas a sua permanência junto aos demais alunos, mas sim uma reorganização nas práticas pedagógicas” o que para as autoras “[...] acarreta a revisão de antigas concepções e paradigmas educacionais na busca de se possibilitar o desenvolvimento cognitivo, cultural e social desses alunos, respeitando suas diferenças e atendendo às suas necessidades".

Sendo assim, o objetivo geral deste estudo foi verificar as possibilidades de associação da leitura de poema clássico à análise de materiais multimodais como proposta para a formação do leitor crítico e participativo, nas aulas de literatura no Ensino Médio incluindo os alunos PAEE. Os objetivos específicos são apresentar e analisar a proposta de intervenção na área de literatura clássica disponível no currículo oficial de Estado de São Paulo; mapear as ações dos alunos, do Ensino Médio, que caracterizam seu envolvimento com a atividade proposta e verificar a disponibilidade e ação dos docentes frente à aplicabilidade da atividade proposta.

\section{REFERENCIAL TEÓRICO}

A oferta do Ensino Médio a partir de marcos legais consubstanciados na Lei de Diretrizes e Bases da Educação Nacional $n^{\circ}$. 9394/96 (BRASIL, 1996) representa um divisor na construção da identidade dessa etapa da Educação Básica brasileira, uma fase de estudos compreendida como o período de consolidação e aprofundamento de muitos conhecimentos construídos ao longo do Ensino Fundamental, pois houve um salto de qualidade determinado por tais diretrizes que consiste na possibilidade objetiva de compreender a função da escola a partir de sua própria realidade, privilegiando o trabalho coletivo.

Nesse contexto, está presente o ensino de literatura, sobretudo a clássica, que apresenta conteúdos organizados em campos de estudo que se entrecruzam e se orientam a partir de questionamentos sociais, levando os adolescentes a refletirem sobre seu próprio modo de 


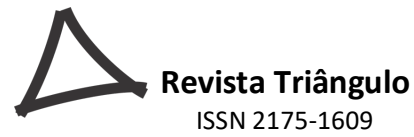

ISSN 2175-1609

vida. (SÃO PAULO, 2010). Assim, justifica-se o uso de práticas com textos da literatura em sala de aula, como aponta Antonio Cândido, "A literatura desenvolve em nós a quota de humanidade na medida em que nos torna mais compreensivos e abertos para a natureza, a sociedade, o semelhante" (CÂNDIDO, 1995, p. 249).

Como objeto de ensino, a literatura clássica permeia todas as séries do Ensino Médio, nos quatro bimestres letivos anualmente. Valoriza-se a interface entre o conhecimento reflexivo de conteúdos literários e o cotidiano cultural em que o aluno está inserido. Desse modo,

\begin{abstract}
O objetivo é que tais conteúdos sejam não apenas "passados", mas que se tornem objeto de constante reflexão. Para esse fim, valorizam-se diferentes esferas de atividades com a linguagem, que a consideram a partir de variadas perspectivas (extra e intralinguísticas), visando a surpreendê-la em sua multiplicidade dinâmica e social (SÃO PAULO, 2010, p. 38).
\end{abstract}

Assim, o estudo da literatura clássica abre-se ao diálogo com diferentes disciplinas, participando nas diversas estratégias de formação do leitor literário.

Zilberman (2003, p. 258) assevera que "a leitura de literária tem-se tornado cada vez mais rarefeita no âmbito escolar, seja porque diluída em meio aos vários tipos de discurso ou de textos, seja porque tem sido substituída por resumos, compilações, etc.”. Ainda segundo a autora, faz-se necessário "o empreendimento de esforços no sentido de dotar o educando da capacidade de se apropriar da literatura, tendo dela a experiência literária".

Para atender às demandas do Ensino Médio, no Currículo do Estado de São Paulo são apresentadas dez Situações de Aprendizagem que intercalam diferentes objetivos literários e sociais "o que possibilita um movimento espiralado de construção de conhecimentos, permitindo assim, retomar as atividades realizadas em outros momentos, analisando-as à luz de novos conceitos construídos em sala de aula" (SÃO PAULO, 2010 p. 39). Cada Situação de Aprendizagem promove a interação de diferentes habilidades esperadas dos adolescentes e o desenvolvimento com conhecimentos específicos dos estudos literários.

Com a chegada do PAEE ao Ensino Médio, como uma das consequências das políticas públicas voltadas à inclusão escolar, houve um olhar mais atento para esse público. Mendes (2002), afirma que a proposta de educação inclusiva tornou-se um dos focos da política educacional vigente, instigada pelos movimentos sociais e tendo como proposta a equiparação de oportunidades para as pessoas até então excluídas. Seguindo este pressuposto traçado em 2002 atualmente estes jovens encontram-se matriculados e freqüentando as escolas de Ensino Médio. 


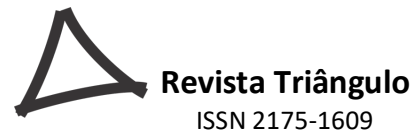

De acordo com a Declaração de Salamanca (UNESCO, 1994), que postula o compromisso da Educação para Todos, "toda criança tem direito fundamental à educação, e deve ser dada a oportunidade de atingir e manter o nível adequado de aprendizagem". Condição está que sustenta a atual Lei de Diretrizes e Bases da Educação Nacional - LDB Lei no 9.394/96.

Em seu artigo 59, inciso I, a LDB 9394/96 define o dever do estado de garantir "o aprimoramento do educando como pessoa humana, incluindo a formação ética e o desenvolvimento da autonomia intelectual e do pensamento crítico". Além disso, estabelece que:

Toda criança possui características, interesses, habilidades e necessidades de aprendizagem que são únicas. As escolas regulares que promovem a cultura inclusiva constituem os meios mais eficazes de combater atitudes discriminatórias criando-se comunidades acolhedoras, construindo uma sociedade inclusiva e alcançando educação para todos (LDB 1996; 2013; 2014; 2015).

Ainda na LDB 9394/96 em seu artigo 59, é firmado que os sistemas de ensino devem assegurar aos alunos currículo, métodos, recursos e organização específicos para atender às suas necessidades.

Com o avanço no estabelecimento da legislação que mapeia as políticas públicas no Brasil as Diretrizes Nacionais para a Educação Especial na Educação Básica, Resolução CNE/CEB n ${ }^{\circ}$ $2 / 2001$, no artigo $2^{\circ}$, determinam que: "Os sistemas de ensino devem matricular todos os alunos, cabendo às escolas organizar-se para o atendimento aos educandos com necessidades educacionais especiais, assegurando as condições necessárias para uma educação de qualidade para todos" (MEC/SEESP, 2001).

Por fim, este pressuposto é incorporado na Política Nacional da Educação Especial na Perspectiva da Educação Inclusiva (BRASIL, 2008) na medida em que mais do que assegurar a matrícula, torna-se obrigatório assegurar a inclusão escolar de alunos com deficiência e garantir o acesso ao ensino regular com participação, aprendizagem e continuidade nos níveis mais elevados do ensino.

Em síntese, é notório que há um consenso crescente no discurso político e pedagógico nos documentos oficiais. Estabelecem o compromisso de todos pela educação para garantir o acesso e permanência no ensino regular e o atendimento às necessidades educacionais especiais do PAEE, fortalecendo a inclusão educacional nas escolas públicas preferencialmente no ensino regular.

Diante desse contexto, há necessidade de adoção de práticas de ensino que atendam a todos e os motivem a alcançar os objetivos propostos, garantindo a inclusão do PAEE entendida 


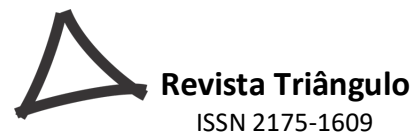

ISSN 2175-1609

como acesso, permanência e aprendizagem. Para que a aprendizagem seja garantida, a multimodalidade se constitui um recurso possível para o desenvolvimento das atividades em sala de aula. A multimodalidade é postulada por Rojo (2009) como "texto multimodal ou multissemiótico que recorre a mais de uma modalidade de linguagem ou a mais de um sistema de signos ou símbolos (semiose) em sua composição”. Ainda segundo a autora:

[...] o desenvolvimento das tecnologias da comunicação com suas práticas sociais específicas de leitura e escrita exige que a escola foque seu trabalho nessa realidade e parta dela para ensinar. A sociedade lida com textos cada vez mais semióticos, que exigem dos alunos estratégias de escrita e também de leitura que estejam de acordo com a multiplicidade de linguagens que compõem o texto: "ocorre que, se houve e se há essa mudança, as tecnologias e os textos contemporâneos, deve haver também uma mudança na maneira como a escola aborda os letramentos requeridos por e por essas mudanças (ROJO, 2011, p. 99).

Nessa perspectiva, Rojo (2009) assevera que os professores, como mediadores, fiquem atentos às novas demandas e criem estratégias que ajudem aos adolescentes ler e interpretar. Trabalhar com a literatura clássica na atualidade requer um olhar mais atento, entender que não se pode criar uma divergência entre leituras clássicas e tecnologias midiáticas, que para Filipouski (2012) são objetos que oferecem variadas possibilidades de interação para o desenvolvimento cognitivo e emocional favorecido pela leitura, pois restauram fora da escola, a importância de "saber ler", ampliam a noção de leitura e podem reintegrar o livro e também a leitura literária - entre os objetos que dão acesso à competência leitora.

Em síntese, a escola brasileira tem dentre suas responsabilidades promover um espaço educacionalmente inclusivo que seja capaz de acolher com competência as necessidades educacionais do PAEE e, sobretudo, buscar estratégias, métodos, recursos, técnicas, além de promover acomodações, adequações e adaptações curriculares de modo a atender seus objetivos no contexto do ensino e da aprendizagem dos alunos.

\section{MATERIAIS E MÉTODOS}

Este trabalho apresenta resultados de uma pesquisa referente à prática curricular proposta pelo Currículo da Secretaria da Educação do Estado de São Paulo - SEE/SP, que está inserida no caderno do professor e do aluno, volume 1, na Situação de Aprendizagem (SA9) intitulada "Quando as palavras resolvem fazer arte!" (SÃO PAULO, 2014).

A metodologia aplicada foi pesquisa ação-participante a qual, segundo Thiollent (1985, p.14), é dividida em quatro fases: exploratória, principal, de ação e de avaliação. Trata-se de uma pesquisa social "[...] no qual os pesquisadores e os participantes representativos da situação da realidade a ser investigada estão envolvidos de modo cooperativo e participativo". O autor explicita que: 


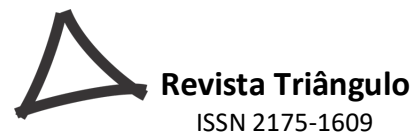

ISSN 2175-1609

[...] pesquisa-ação é uma estratégia metodológica da pesquisa social na qual [...] há, durante o processo, um acompanhamento das decisões, das ações e de toda a atividade intencional dos atores da situação; a pesquisa não se limita a uma forma de ação (ativismo): pretende-se aumentar o conhecimento dos pesquisadores e o conhecimento ou o 'nível de consciência' das pessoas e grupos considerados (THIOLLENT, 1986, p.16).

Para este estudo, optou-se por analisar somente a atividade da SA9 que utilizou os recursos com materiais multimodais, pois ela proporciona aos adolescentes diferentes oportunidades de aprendizagem, visto que eles vivem em meio a diferentes modos de leitura, mídias e estão imergidos no universo de tecnologias em que os atrativos sonoros e visuais são fascinantes, além do que, essas inserções podem conduzir um maior envolvimento e garantir o acesso ao currículo ao aluno PAEE.

Como instrumentos de coleta de dados, foram utilizados o Kit do Currículo Oficial da $\mathrm{SEE} / \mathrm{SP}$, contendo o material do professor e do aluno; os registros das práticas, as entrevistas realizadas pelos adolescentes com outras turmas e com os dois docentes de Língua Portuguesa, bem como as produções textuais dos alunos espelhadas em um poema clássico.

A escola lócus da pesquisa localiza-se no interior paulista e no ano de 2017 contava com seis turmas de $1^{\text {a }}$ série do Ensino Médio. A professora-pesquisadora ministrava aulas em apenas duas. Os outros dois docentes de Língua Portuguesa não eram titulares de cargo, entretanto, tinham estabilidade e mantinham por vários anos a mesma turma. $\mathrm{O}$ docente 1 , a partir daqui denominado D1, possuía 20 anos de carreira, dos quais 12 na mesma unidade escolar. $\mathrm{O}$ docente 2 (D2) tinha 20 anos no magistério e 10 na mesma unidade escolar, condição esta que poderia possibilitar um trabalho pedagógico e metodológico planejado para atender às especificidades de cada aluno, uma vez que tinha amplo conhecimento da clientela atendida pela escola.

As atividades foram desenvolvidas durante o ano letivo com duas turmas da $1^{\text {a }}$. Série do Ensino Médio que participaram juntamente com a professora-pesquisadora. Dentre os alunos sujeitos da pesquisa, quatro estão identificados e cadastrados no sistema da Secretaria da Educação do Estado de São Paulo - GDAE (Gestão Dinâmica de Administração Escolar), com deficiência Intelectual (DI).

Os alunos PAEE são definidos aqui como A1, A2, A3 e A4. O A1 tinha 16 anos, do sexo masculino era alfabetizado, porém tinha dificuldade de aprendizagem. As alunas A2 e A3 são do sexo feminino, tinham 17 anos. A A2 era muito participativa, não apresentava dificuldade para escrever, o que não ocorria com a leitura. Já a aluna A3 tinha dificuldade na aprendizagem e desafazem nos conteúdos. A aluna A4 tinha 16 anos, do sexo feminino e também apresentava defasagem nos conteúdos e dificuldade de interpretação. 


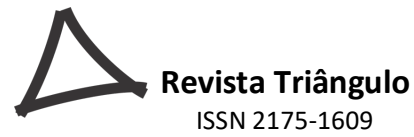

ISSN 2175-1609

A primeira etapa, caracterizada como sondagem inicial, teve início mediante solicitação para que os alunos trouxessem um texto que considerassem "bonito" ou "belo". Realizou-se uma roda de conversa cujo objetivo foi a apresentação dos motivos de suas escolhas. Posteriormente, foram convidados a ler e analisar o soneto de Camões intitulado "Julga-me a gente toda por perdido" que aborda a relação difícil entre o indivíduo e a sociedade; o eu lírico age de maneira diferente devido ao amor por sua dama e é incompreendido pelas pessoas. Foram propostas algumas questões norteadoras para mediar discussões tais como: Esse soneto é considerado uma obra de arte? Vocês conseguem imaginar por quê? Quem decide que textos devem ou não ser considerados obras de arte? Em sua opinião, que características um texto precisa apresentar para ser considerado uma obra de arte?

Na segunda etapa, foi feita uma atualização do poema lido, ou seja, uma transformação do gênero textual poema para letra de música moderna e no contexto de recepção - renascimento dos jovens estudantes do século XXI. A transformação, no entanto, deveria manter a parte escrita do poema original camoniano. Para tanto, também seria necessário levar em conta a questão do ritmo. A atividade desenvolvida consta no material da SEE-SP, caderno do professor com a seguinte comando:

Pedro gosta muito de escrever letras de música e ele as faz de todos os tipos: sambas, raps, baladas. Com ele não tem problema, apenas precisa de uma inspiração. Sua namorada, Beloniza, pediu-lhe para "transformar" o soneto de Camões "Julga-me a gente toda por perdido" em uma letra de música moderna, mantendo as mesmas ideias, mas mudando as palavras, a divisão das estrofes, o que ele quisesse. No caderno, assuma o lugar de Pedro e faça essa adaptação (SÃO PAULO, 2014, p. 90).

$\mathrm{Na}$ terceira etapa, após a aplicação da atividade supracitada, solicitou-se que os adolescentes realizassem entrevistas com a turma dos quatro primeiros anos do Ensino Médio, nos quais a professora-pesquisadora não ministrava aulas de literatura, com as perguntas norteadoras: Vocês gostam de ler poemas? E ouvir ou escrever músicas? No caderno do aluno, há uma atividade sobre o poema de Camões. Vocês realizaram? Foi interessante?

A quarta etapa consistiu na realização de entrevistas com dois docentes de Língua Portuguesa que ministram aulas no Ensino Médio. As perguntas foram: Você acha importante trabalhar com atividades próximas da realidade do adolescente? Como foi realizada a SA9 com sua turma? Os alunos participaram de forma efetiva e significativa? A maneira que está inserida no caderno é pertinente? Você mudaria alguma coisa?

A quinta e última etapa foi a fase de avaliação em que os alunos refletiram sobre suas ações e discutiram a participação do trabalho em pares, em favor da construção de conhecimentos, do desenvolvimento pessoal e do engajamento nas atividades. 


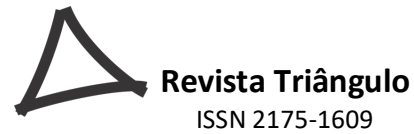

ISSN 2175-1609

\section{ANÁLISE DOS DADOS E RESULTADOS}

Na primeira etapa, caracterizada como sondagem, que é a fase exploratória e inicial postulada por Thiollent (1985), na qual são descritos os conhecimentos prévios que os adolescentes trazem para sala de aula, verificou-se que alguns conheciam os poemas de Camões por circularem nas diferentes mídias, entretanto, não sabiam a autoria, somente depois da roda de conversa que foram surgindo as interrelações. Um aluno PAEE destacou-se, pois participou da roda de conversa com os colegas, fez suas contribuições e colocou que conhecia um poema de Camões que falava de amor por meio de uma propaganda que circulou na mídia.

A roda de conversa é um instrumento que pode facilitar a aprendizagem. Warschauer (2001) afirma que:

Conversar não só desenvolve a capacidade de argumentação lógica, como, ao propor a presença física do outro, implica as capacidades relacionais, as emoções, o respeito, saber ouvir e falar, aguardar a vez, inserir-se na malha da conversa, enfrentar as diferenças, o esforço de colocar-se no ponto de vista do outro etc. [...] (WARSCHAUER, 2001, p. 179).

E, ao adotar esse instrumento, considera-se que o diálogo construído representa o pensar e o falar de "[...] indivíduos com histórias de vida diferentes e maneiras próprias de pensar e de sentir, de modo que os diálogos, nascidos desse encontro, não obedecem a uma mesma lógica”. (WARSCHAUER, 2001, p. 46). Assim, a roda de conversa gera trocas de experiências importantes para o desenvolvimento de todos.

As questões foram debatidas intensamente, de modo a aprofundar os conteúdos necessários para contemplar as competências e habilidades exigidas pela situação de aprendizagem.

Os adolescentes utilizaram seus repertórios pessoais, refletiram sobre o conceito de belo, responderam e argumentaram sobre seus pontos de vista de forma coerente, independentemente de suas especificidades como pode-se observar pela fala do aluno A1, que faz parte do PAEE.

"Professora depois que eu conheci os textos de Camões passei a gostar mais de poema. Eu achava muito difícil entender. Esse poema que lemos é uma obra de arte porque é alguém que fez com muito carinho para outras pessoas ver e quando essas pessoas gostam, vira uma obra de arte".

Nessa perspectiva, Correia (2003, p. 41) assevera que "[...] as necessidades, os interesses, as características e os estilos de aprendizagem dos alunos, requer a utilização de práticas educativas flexíveis e as estratégias e o material usado devem ser, sempre que possível, concretos e estimulantes". 


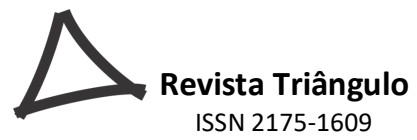

ISSN 2175-1609

$\mathrm{Na}$ segunda etapa, os adolescentes fizeram atividades de modo que todos participaram. Trabalharam de forma coletiva, aprimorando suas condições de leitores e produtores sociais. Por iniciativa própria, fizeram uma gravação baseada na letra da música produzida, colocaram sons e ritmos. Dessa forma, foram além das expectativas que a professorapesquisadora havia traçado inicialmente.

Essas atividades foram estimulantes e favoreceram o aprimoramento de competências como a comunicação, a colaboração e a liderança compartilhada, que são fundamentais para inserção de forma crítica e participativa na vida cidadã.

Para este texto, optou-se por mostrar apenas três produções textuais dos alunos para análise: um aluno PAEE com Deficiência Intelectual e dois sem deficiência, identificados aqui como Aluno A, B e C. 


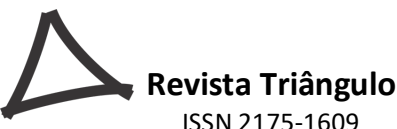

ISSN 2175-1609

Quadro 4: Produção textual dos alunos

\begin{tabular}{|c|c|c|}
\hline Aluno $A$ & Aluno B & Aluno $C$ \\
\hline 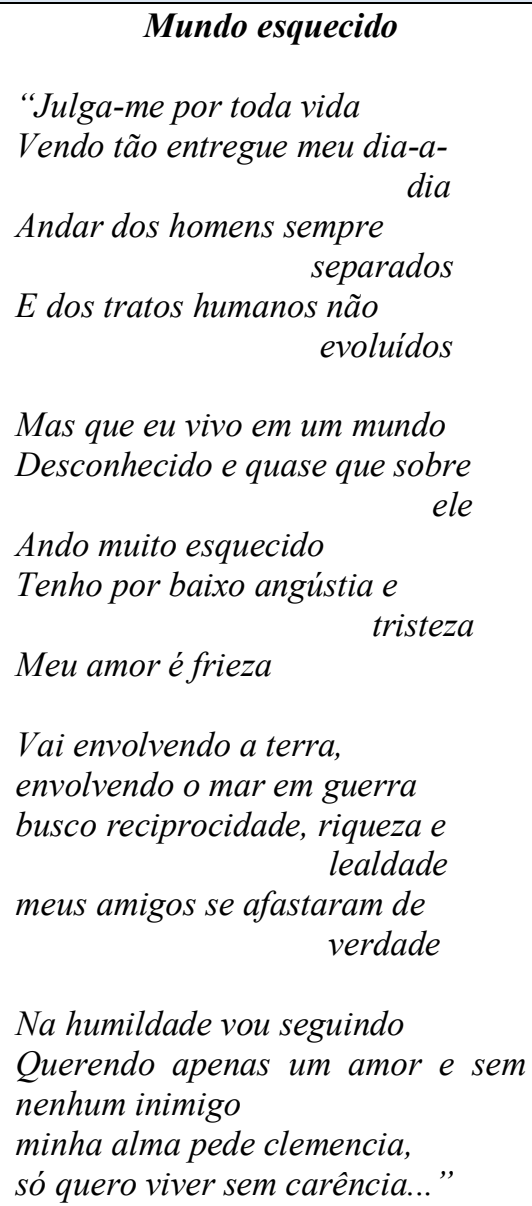 & $\begin{array}{c}\text { Amor isolado } \\
\text { “Eu não compreendo esta } \\
\text { sociedade } \\
\text { Não tem igualdade muito menos } \\
\text { humildade, } \\
\text { Quero calma e dedicação } \\
\text { Pra trazer lembrança da amada do } \\
\text { meu coração } \\
\text { Estou isolado nesse mundão } \\
\text { Pois sempre que penso nela caio } \\
\text { no chão } \\
\text { Larguei tudo para ir atrás de } \\
\text { minha amada, } \\
\text { Corri e peguei essa estrada } \\
\text { isolada. } \\
\text { A chuva caiu e meu amor sumiu } \\
\text { Vá envolvendo a terra, o mar e o } \\
\text { vento } \\
\text { Sozinho nesse mundo, trago } \\
\text { Comigo esse sentimento. }\end{array}$ & $\begin{array}{l}\text { “O sentimento não se } \\
\text { esquece } \\
\text { dentro da alma permanece } \\
\text { se um dia te dissese } \\
\text { o amor, a alma engrandece } \\
\text { tenho me contentado com } \\
\text { pouco } \\
\text { amargurando esse sufoco } \\
\text { conhecem o mundo } \\
\text { tem ele debaixo do braço } \\
\text { não se conhecem sobre } \\
\quad \text { tudo } \\
\text { meu bem, se lembre bem } \\
\text { riqueza não é material } \\
\text { amo te sobre tudo e além”. }\end{array}$ \\
\hline
\end{tabular}

Fonte: Elaborado pela autora com as produções dos alunos

Verificou-se que os alunos A e B conseguiram realizar o comando do exercício e as habilidades e competências exigidas pela atividade foram contempladas. $\mathrm{O}$ aluno A, que é PAEE, fez a transformação de gênero textual e o contexto de recepção também foi mudado. O mesmo manteve a escrita original com as mesmas ideias e atentou para a questão do ritmo. Além disso, houve presença de rimas e clareza na construção da letra verificando, desse modo, que os conceitos de verso, estrofe e rimas foram assimilados.

$\mathrm{O}$ aluno $\mathrm{C}$ que não faz parte do $\mathrm{PAEE}$, embora tenha recebido os mesmos comandos do exercício e utilizadas as mesmas estratégias para que pudesse atender ao que se pedia, não atingiu plenamente as habilidades e competências que eram exigidas, pois tangenciou o tema e não colocou título. 


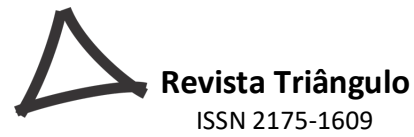

A análise das produções escritas permitiu concluir que, quando criadas oportunidades de atitudes e parcerias entre professores e alunos para praticarem ações voltadas para o acolhimento, criatividade e liberdade, a aprendizagem acontece e todos os alunos independentemente de serem PAEE conseguem avançar. Foi possível verificar maior engajamento dos estudantes no desenvolvimento das atividades relacionadas à produção escrita.

Assim, trabalhar com literatura clássica na atualidade não pode ser encarado como uma imposição curricular, mas como um “[...] momento do exercício de percepção e de incorporação de um tipo de discurso ou comportamento linguístico que corresponde ao exercício pleno da liberdade criadora" (FREDERICO; OSAKABE, 2004, p. 79).

O envolvimento dos alunos na atividade foi determinante para a aprendizagem do conteúdo. Acredita-se que esse engajamento seja devido ao uso dos materiais multimodais. A multimodalidade é postulada por Rojo (2009) como texto multimodal ou multissemiótico que recorre a mais de uma modalidade de linguagem ou a mais de um sistema de signos ou símbolos (semiose) em sua composição.

$\mathrm{O}$ desenvolvimento da atividade trouxe maior envolvimento e autonomia para os adolescentes participantes da pesquisa, pois passaram a ler outros poemas e ter acesso à internet e à sala da leitura da escola sem a mediação do professor. Além disso, a postura que os alunos demonstraram frente à atividade corrobora com a ideia de que:

[...] na leitura e na escritura do texto literário, encontramos o senso de nós mesmos e da comunidade a que pertencemos. A literatura nos diz o que somos e nos incentiva a desejar e a expressar o mundo por nós mesmos" E isso se dá porque a Literatura é uma experiência a ser realizada. É mais que um conhecimento a ser reelaborado, ela é a incorporação do outro em mim sem renúncia de minha própria identidade (COSSON, 2012, p. 17).

$\mathrm{Na}$ terceira etapa foram realizadas, pelos alunos, as entrevistas com os adolescentes das quatro turmas da $1^{\text {a }}$. Série do Ensino Médio, cujas respostas foram registradas e, posteriormente, organizadas em categorias de acordo com as perguntas e sintetizadas conforme descrito no quadro abaixo. Uma aluna PAEE destacou-se bastante, pois fez as perguntas para os professores, de maneira clara, sem timidez, anotando no caderno as respostas para coletar os dados. Foi uma grande oportunidade para todos os alunos envolvidos trabalharem como protagonistas. 


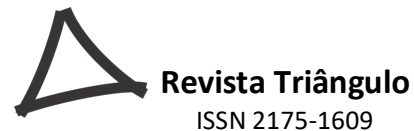

ISSN 2175-1609

Quadro 1: Análise da entrevista com os alunos das outras turmas

\begin{tabular}{|l|l|}
\hline Questão da Entrevista & Síntese das respostas \\
\hline 1.Vocês gostam de ler poemas? & $\begin{array}{l}\text { A maioria dos adolescentes disse que não lê poemas, pois não entende } \\
\text { muito, precisa parar e pensar no que está escrito. No entanto, verificou-se } \\
\text { que dois deles têm bastante interesse pela poesia. }\end{array}$ \\
\hline 2. E ouvir ou escrever músicas? & $\begin{array}{l}\text { Ouvir músicas foi unanimidade entre eles. Houve um consenso entre eles } \\
\text { de que a música faz parte do dia a dia e ajuda na hora de estudar. Dois } \\
\text { estudantes têm muita facilidade de compor poemas e letras de música. }\end{array}$ \\
\hline $\begin{array}{l}\text { 3. No caderno do aluno, Situação } \\
\text { de Aprendizagem 9 há uma } \\
\text { atividade sobre o poema de de } \\
\begin{array}{l}\text { Camões. Vocês realizaram? Foi } \\
\text { interessante? }\end{array}\end{array}$ & $\begin{array}{l}\text { nenhuma atividade da SA. Disseram que a professora pulou essa atividade } \\
\text { porque estava atrasada com o conteúdo. } \\
\text { As duas restantes, que tem como responsável o D2, fizeram somente } \\
\text { algumas atividades, assinalando as respostas corretas. Os exercícios que } \\
\text { utilizavam os materiais multimodais não foram contemplados. } \\
\text { A maioria dos alunos disse que foi normal e gostou de fazer. }\end{array}$ \\
\hline
\end{tabular}

Fonte: Elaboração da autora com as respostas às entrevistas

Quanto à leitura de poemas, ficou evidente que para os alunos esse gênero textual, em um primeiro momento, gera certo desconforto, pois trata-se de um texto que precisa de leitura mais atenta, que nem sempre é fluida. Exige dedicação, um engajamento do leitor, uma entrega que, muitas vezes, não é de consumo rápido, como os adolescentes estão acostumados, mas que requer concentração, compreensão e reflexão.

Para Pinheiro (2008) uma boa leitura ou uma leitura significativa estará sempre a nos exigir tempo, reflexão, análise detida das obras, além da concepção de que " [...] o prazer de ler, tão badalado, nasce do esforço, do trabalho. Poemas, contos, crônicas, dramas, são gêneros que, assim como os romances, têm suas próprias exigências de fruição e estudo". (PINHEIRO, 2006, p. 119).

Para corroborar com essas ideias, é possível acrescentar que:

\begin{abstract}
Quando não conhecemos algo, o significado de alguma palavra, um lugar, um som ou um determinado contexto é natural que sintamos um medo ou, pelo menos, uma ansiedade que incomoda. Porém, quando passamos a entender o que nos é estranho, nos perturba, o temor que nos atingia desaparece e passamos a compreender e a decodificar o que antes era um mistério, uma dificuldade e, então, somos capazes de decidir por nós mesmos o que é melhor para cada situação apresentada (GUIMARÃES; RODRIGUES, 2015, p. 18).
\end{abstract}

Assim, para que os adolescentes não tenham estranhamento ao ler poemas, faz-se necessário uma construção diária para que percebam que a poesia está presente em suas vidas o tempo todo, basta buscá-la. Os educadores precisam criar mais estratégias que permitam "[...] o educando realizar a sua própria aprendizagem, conforme seus próprios interesses, 


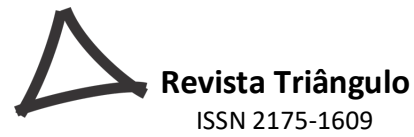

ISSN 2175-1609

necessidades, fantasias, segundo as dúvidas e exigências que a realidade lhe apresenta" (MARTINS, 2007, p. 34). Dessa forma, cria-se um diálogo entre o leitor e leitura, e o professor torna-se um mediador para a formação de adolescentes críticos, conscientes e participativos não só na aula de literatura, mas nas suas vidas.

Nessa perspectiva, a escola não pode ficar distante do universo juvenil, afastada das possibilidades e interesses dos jovens, sobretudo do Ensino Médio, valendo-se apenas de livros didáticos ou estratégias tradicionais que, muitas vezes, fazem com que os mesmos se tornem desmotivados.

[...] é desejável adotar uma perspectiva multicultural, em que a Literatura obtenha a parceria de outras áreas, sobretudo artes plásticas e cinema, não de um modo simplista, diluindo as fronteiras entre elas e substituindo uma coisa por outra, mas mantendo as especificidades e o modo de ser de cada uma delas, pois só assim, não pejorativamente escolarizados, serão capazes de oferecer fruição e conhecimento, binômio inseparável da arte (BRASIL, 2006, p. 74).

Em relação à questão dois, verificou-se que ouvir música faz parte do cotidiano dos adolescentes, conseguem fazer suas atividades e ao mesmo tempo navegar pela internet, escrever textos ouvindo músicas. Dessa forma, se ficarmos atentos a essa nova forma de viver dos jovens, os educadores poderão descobrir que eles ensinam a não criar um antagonismo entre leituras e tecnologias midiáticas, mostrando a todo momento que "também se aprende a ler e a ser espectador sendo telespectador e internauta", e que "ser internauta aumenta, para milhões de pessoas, a possibilidade de serem leitores e espectadores" (CANCLINI, 2008, p. 24-54).

Quanto à aplicabilidade da Situação de Aprendizagem nove, questão três, as turmas do D1 não realizaram nenhuma atividade. Acredita-se que o fato de ser uma situação que requer um planejamento prévio e demanda tempo, infere-se a hipótese a ser considerada de o docente, provavelmente esgotado pelos ritmos de pronto atendimento imposto pelo sistema, dos quais muitas vezes, visa não à aprendizagem, mas somente a apresentação do conteúdo, optou por não realizar as atividades.

O D2 realizou somente algumas atividades, cumprindo de acordo com os adolescentes, o protocolo sugerido, ou seja, respondendo somente às questões que de múltipla escolha. Os exercícios que utilizavam os materiais multimodais não foram contemplados, como a transformação do poema camoniano em letra de música. Entretanto, as respostas dos alunos foram positivas, gostaram de fazer, mesmo sem utilizar outros recursos e mídias, como podese observar na fala do aluno:

"Eu gostei de fazer essas atividades, fomos lendo junto com a professora e respondendo as perguntas. Falava sobre o poema de camões e da dificuldade de 


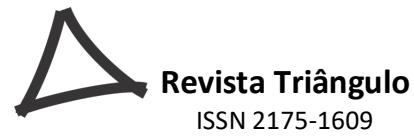

ISSN 2175-1609

relacionamento porque era diferente das pessoas, amava muito. Tinha umas palavras diferentes que eu não conhecia e a professora ajudou. Eu prefiro atividade de assinalar do que escrever texto".

$\mathrm{Na}$ quarta etapa, verificou-se que os docentes acreditam na importância de se valorizar práticas pedagógicas que vão ao encontro das expectativas dos adolescentes e não mudariam a maneira como a SA9 está inserida no currículo, como podemos verificar na fala do D1:

"Eu acho muito importante trabalhar com atividades próximas da realidade do
aluno, pois eles participam mais, ficam animados e a aula fica mais fácil de ser
trabalhada. A forma como está inserida no caderno do aluno está muito boa, pois
está de acordo com os conteúdos e temas necessários para a aprendizagem da SA9".

Entretanto, quando o D1 foi indagado sobre a realização da SA 9, meneou a cabeça e disse que os alunos não conseguiriam fazê-la, sugerindo que eles não fossem competentes. Já o D2 respondeu que cumpriu somente as atividades que eram de múltipla escolha, pois estava atrasado com conteúdo havendo participação dos alunos nas atividades, respondendo às alternativas sem problemas.

Cabe aqui salientar que em nenhum momento os docentes mencionaram o PAEE, confirmaram a relevância da atividade e o contexto para sua realização, entretanto, esse público ainda parece ser invisível para a maioria dos educadores.

Ora, se ambos acreditam na importância do trabalho contextualizado, qual seria, então, o motivo de não trabalharem ou privilegiarem somente algumas atividades?

Novamente, aqui é possível considerar a hipótese de que a razão dos docentes não desenvolverem as atividades que utilizavam a multimodalidade na SA9, deve-se ao fato de estarem, muitas vezes, cansados ou até mesmo desamparados pelo sistema que cerceia as possibilidades de inovação.

De acordo as Orientações Curriculares para o Ensino Médio (2008, p.76), “[...] a noção de que é necessário cobrir toda a extensão da história da literatura no ensino médio acaba exilando o contato com as obras da sala de aula; torna-se ainda uma pressão sobre o professor, acarretando em aulas desinteressantes [...]". Ainda assevera que:

Os professores, pressionados por programas panorâmicos, sentem-se obrigados a cobrir toda a linha do tempo (assim como se sentem pressionados a cobrir todos os pontos da gramática), fazendo uso da história da literatura, ainda que isso não sirva para nada: aulas "chatas", alunos e professores desmotivados, aprendizagem que não corresponde ao que em princípio foi ensinado. (BRASIL, 2008, p. 76). 


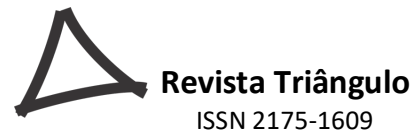

ISSN 2175-1609

A quinta e última etapa foi a fase de avaliação muito importante para o encerramento da proposta, pois alunos e professores exerceram a atitude de abertura para avaliação e resultados das ações. Esse instrumento foi essencial para que se descobrisse as conquistas e pontos que precisavam ser aprimorados tanto a prática docente quanto à aprendizagem. Um aluno PAEE exteriorizou que se sentia feliz em participar da atividade, pois o colega da outra turma o ajudou a colocar o ritmo e fazer a gravação do vídeo, sugerindo que todos os professores fizessem esse tipo de atividade, pois assim todos participariam, ou seja, sentiu-se incluído e acolhido.

Nessa perspectiva, reitera-se a importância do educador como mediador durante as atividades, para que seja possível criar um ambiente de liberdade, respeito e diálogo, que são condições essenciais para uma aprendizagem significativa e inclusiva nas aulas de literatura.

Refletindo sobre os aspectos positivos de usar a multimodalidade Rojo (2009) sustenta que quando adolescentes aprendem se divertindo, também estão estimulando e desenvolvendo aspectos estruturais, elementos estes que podem ser aproveitados e incentivados dentro da sala de aula no processo de ensino-aprendizagem.

Diante disso, é cada vez mais necessário conhecer e considerar os interesses dos adolescentes, bem como suas estratégias de comunicação e aprendizagem. Assim, pode-se proporcionar a eles uma aprendizagem significativa mais próxima do seu cotidiano. Assim, a abordagem da multimodalidade associada à leitura de poema clássico pode contribuir para a formação do leitor crítico e participativo nas aulas de literatura e nas mais diversas práticas contemporâneas.

Nessa perspectiva, compreende-se que quando são utilizadas práticas que culminem com a realidade dos adolescentes em sala de aula e atenda às diferenças existentes entres eles, promove-se uma maior motivação e interesse na realização das atividades, proporcionando um novo caminhar para trabalhar não só com a literatura clássica, mas também com a contemporânea na perspectiva inclusiva. Dessa forma, "todos ganham, pois, crianças com deficiência convivem com modelos enriquecedores e desafiadores e as crianças ditas normais, aprendem, desde cedo a lidar com as diferenças" (MELCHIORI et. al., 2009, p.57).

Portanto, "para se discutir inclusão escolar é preciso pensar antes de tudo em melhorar a escola e o ensino para todos os alunos. Além disso, é necessário "melhorar a qualidade do ensino comum para poder se avaliar o quanto essa escolarização qualificada na classe regular pode fazer pela educação de crianças com necessidades educacionais especiais [...]" (MENDES; VILARONGA, 2014, p.37). 


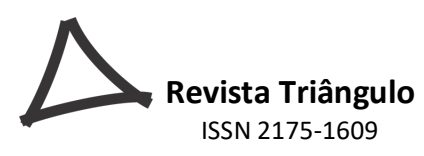

ISSN 2175-1609

\section{CONSIDERAÇÕES FINAIS}

Ao se recuperar o objetivo que norteou o desenvolvimento deste trabalho, verificou-se que tanto estudantes PAEE quanto os demais utilizaram estratégias cognitivas que os possibilitaram a realização das atividades propostas, de modo a atingir as competências e habilidades que eram esperadas. A utilização de música aliada ao estudo do poema da literatura clássica no contexto educativo promoveu maior motivação e interesse na realização das atividades, colocando o adolescente no papel de protagonista do processo de ensinoaprendizagem.

Nesse sentido, acredita-se que é cada vez mais necessário instrumentalizar os estudantes para a utilização dos materiais multimodais e incorporá-los nos contextos escolares, de modo que sejam articulados com o currículo, visando à maior inserção dos adolescentes nas práticas letradas, permitindo o aprimoramento de suas condições de leitores e produtores sociais que favoreçam o processo de ensino-aprendizagem. Desse modo, os educadores não precisam ficar engessados, podem desprender-se de práticas tradicionais e/ou cristalizadas que muitas vezes discriminam, segregam e vivenciar novos caminhos mais estimulantes tanto para si, quanto para os adolescentes.

Compreende-se que, com a valorização de práticas pedagógicas que vão ao encontro das expectativas dos adolescentes, sobretudo do Ensino Médio, todos os alunos serão beneficiados, independentemente de serem PAEE, uma vez que a multimodalidade aproximase das preferências e realidade do atual contexto midiático que o adolescente está inserido.

Ter deficiência nem sempre é um fator impeditivo para a aprendizagem do PAEE. Há necessidade de adaptação, ajuste, orientação individual para garantir o acesso ao conteúdo previsto. Não ter deficiência nem sempre é um fator que garante a aprendizagem. Assim, os ajustes, as adaptações, as flexibilizações para atender as necessidades do PAEE tornam-se facilitadores para a aprendizagem de todos.

Portanto, a presença de alunos com deficiência na sala de aula comum não constitui um fator impeditivo para garantir a todos o acesso ao conteúdo, sendo esse o objetivo central da educação, ou seja, possibilidades de aprendizagem garantidas para todos.

\section{REFERÊNCIAS}

BRASIL. Ministério da Educação (MEC). Secretaria de Educação Básica (SEB). Orientações curriculares para o ensino médio. Brasília: MEC, SEB, 2008. V. 1: Linguagens, códigos e suas tecnologias. 


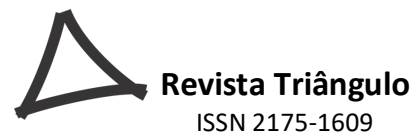

ISSN 2175-1609

BRASIL. Lei n. 9.394, de 20 de dezembro de 1996. Estabelece as diretrizes e bases da educação nacional. Diário Oficial da União, Brasília, DF, 23 dez. 1996, v. 134, n. 248, seção I, p. $27833-27841$.

BRASIL. Declaração Mundial sobre Educação para Todos: plano de ação para satisfazer as necessidades básicas de aprendizagem. UNESCO, Jomtiem/Tailândia, 1990.

BRASIL. Ministério da Educação (MEC). Secretaria de Educação Fundamental (SEF). Parâmetros curriculares nacionais: terceiro e quarto ciclos. Língua

Portuguesa. Brasília: MEC, SEF, 2008.

BRASIL. Ministério da Educação. Secretaria de Educação Especial. Diretrizes Nacionais para a Educação Especial na Educação Básica. Secretaria de Educação Especial MEC/SEESP, 2001.

BRASIL. Ministério da educação/secretaria de educação básica. Orientações Curriculares Nacionais para o Ensino Médio: Linguagens, Códigos e suas Tecnologias. Brasília: MEC, 2006. (http://portal.mec.gov.br/seb/arquivos/pdf/book_volume 01_internet.pdf)

CANCLINI, N. G. Leitores, espectadores e internautas. São Paulo: Iluminuras, 2008.

CORREIA, L.M. Alunos com Necessidades Educativas Especiais nas classes regulares. Porto: Porto Editora, 1997.

COSSON, R. Letramento Literário. São Paulo: Contexto, 2006.

FILIPOUSKI, A. R. Formação de leitores de literatura juvenil na escola contemporânea: tarefa (im)possível?, São Paulo, v. 18, n.18, p. 160, 2012.

FREDERICO, Enid Yatsuda; OSAKABE, Haquira. PCNEM - literatura. Análise crítica. In: Brasil. Ministério da Educação (MEC). Secretaria de Educação Básica (SEB).

GLAT, R.; NOGUEIRA, M. L. de L. Políticas educacionais e a formação de professores para a educação inclusiva no Brasil. In: Revista Integração. Brasília: Ministério da Educação/Secretaria de Educação Especial, ano 14, vol. 24, 2002.

GUIMARÃES, A. H. T.; RODRIGUES, S. D. A. O uso da literatura contemporânea para o ensino de leitura e literatura no ensino médio: uma proposta de acordo com os preceitos freirianos. In: Revista Colineares, ano 15, n. 2, vol. 2, 2015.

MARTINS, M. H. O que é leitura. 19.ed. São Paulo: Editora Brasiliense, 2007.

MELCHIORI, L. E.; LEPRE, R. M.; MARTINS, M. F. A. O desenvolvimento humano e sua importância na aprendizagem. In: CAPELLINI, V. L. F.; RODRIGUES, O. M. P. R. (Org). Fundamentos da educação inclusiva. Bauru-SP, UNESP/FC, 2009.

\begin{tabular}{l|l|l|l|l|} 
(C) Revista Triângulo & Uberaba, MG & v.12 & n.1 & p. 24-42
\end{tabular}
Jan. / Abr. 2019 
MENDES, E. G.; VILARONGA, C. A. R. Inclusão escolar e a formação do professor para o ensino colaborativo ou co-ensino no Brasil. In: SADAO, O; BRAGA, T. M. S.; CHACÓN, M. C. M.; MONTALVO, D. (Editores). Reflexiones internacionales sobre La formación de profesores para la atención a los alunos com necesidades educativas especiales. Universidad de Alcalá, Alcalá de Henares (Espanha, 2014).

PINHEIRO, Hélder. Teoria da literatura, crítica literária e ensino. In:

Nóbrega, Marta (Orgs). Literatura: da crítica à sala de aula. Campina Grande:

Bagagem, 2006. p. 111-126.

ROJO, R. Letramentos múltiplos, escola e inclusão social. São Paulo: Parábola Editorial, 2009.

SEE/SP. Secretaria da Educação do Estado de São Paulo. Caderno do professor, (Língua Portuguesa). São Paulo: IMESP, 2014.

Caderno do aluno, (Língua Portuguesa). São Paulo: IMESP, 2014.

THIOLlENT, M. (1986). Metodologia da Pesquisa-Ação. São Paulo: Cortez.

SILVA, M.; PEREIRA, M. M. Letramento Literário e Ensino de Literatura no Ensino Médio. Dialogia, São Paulo: n. 26, p. 37-52, maio/ago. 2017.

UNESCO. Declaração de Salamanca e Enquadramento da Ação na Área das

Necessidades Especiais. In: Conferência Mundial sobre Educação para as Necessidades Especiais: Acesso e Qualidade, Salamanca. Disponível em:

$<\mathrm{http}$ //www.portal.mec.gov.br/seesp/arquivos/pdf/ salamanca.pdf>. Acesso: 9 jan. 2018.

WARSCHAUER, C. Rodas em rede: oportunidades formativas na escola e fora dela. Rio de Janeiro: Paz e Terra, 2001.

\begin{tabular}{|l|l|}
\hline \multirow{2}{*}{$\begin{array}{l}\text { Recebido em: 13 Jan. } 2019 \\
\text { Aprovado em: } 18 \text { Abr. } 2019\end{array}$} \\
\hline
\end{tabular}

